\title{
Persistent barrage firing in cortical interneurons can be induced in vivo and may be important for the suppression of epileptiform activity
}

\author{
Norimitsu Suzuki, Clara S.-M. Tang ${ }^{\dagger}$ and John M. Bekkers* \\ Eccles Institute of Neuroscience, The John Curtin School of Medical Research, The Australian National University, Canberra, ACT, Australia
}

\section{Edited by:}

Rena Li, Roskamp Institute, USA

\section{Reviewed by:}

Enrico Cherubini, International School for Advanced Studies, Italy

Laurens Bosman, Erasmus University Medical Center, Netherlands

\section{*Correspondence:}

John M. Bekkers, Eccles Institute of Neuroscience, The John Curtin School of Medical Research, Building 131, The Australian National University, Canberra, ACT 2601, Australia e-mail: john.bekkers@anu.edu.au

\section{${ }^{\dagger}$ Present address:}

Clara S.-M. Tang, Department of Physiology, Development and Neuroscience, University of Cambridge, Cambridge CB2 3EG, UK
Neural circuits are typically maintained in a state of dynamic equilibrium by balanced synaptic excitation and inhibition. However, brain regions that are particularly susceptible to epilepsy may have evolved additional specialized mechanisms for inhibiting over-excitation. Here we identify one such possible mechanism in the cerebral cortex and hippocampus of mice. Recently it was reported that some types of GABAergic interneurons can slowly integrate excitatory inputs until eventually they fire persistently in the absence of the original stimulus. This property, called persistent firing or retroaxonal barrage firing (BF), is of unknown physiological importance. We show that two common types of interneurons in cortical regions, neurogliaform (NG) cells and fast-spiking (FS) cells, are unique in exhibiting BF in acute slices ( $\sim 85$ and $\sim 23 \%$ success rate for induction, respectively). BF can also be induced in vivo, although the success rate for induction is lower ( $60 \%$ in NG cells). In slices, BF could reliably be triggered by trains of excitatory synaptic input, as well as by exposure to proconvulsant bath solutions (elevated extracellular $\mathrm{K}^{+}$, blockade of $\mathrm{GABA}_{A}$ receptors). Using pair recordings in slices, we confirmed that barrage-firing NG cells can produce synaptic inhibition of nearby pyramidal neurons, and that this inhibition outlasts the original excitation. The ubiquity of NG and FS cells, together with their ability to fire persistently following excessive excitation, suggests that these interneurons may function as cortical sentinels, imposing an activity-dependent brake on undesirable neuronal hyperexcitability.

Keywords: action potential, inhibition, interneuron, neurogliaform, patch clamp, piriform cortex, seizure, synapse

\section{INTRODUCTION}

The computational power of cortical microcircuits is thought to be enhanced by the presence of recurrent excitatory connections that can selectively amplify weak inputs. However, this type of architecture is potentially dangerous because overexcitation may lead to seizures (Shepherd, 2011). To counter this tendency, the cortex contains various types of inhibitory circuits that maintain the network in a state of dynamic equilibrium. Here we explore the idea that a recently described feature of some types of GABAergic interneurons, called persistent firing (Sheffield et al., 2011) or retroaxonal barrage firing (BF; Sheffield etal., 2013), may equip those interneurons with an additional mechanism for protecting against cortical over-excitation.

Persistent or retroaxonal barrage firing (which we will call "BF") is an unusual kind of slow integration of synaptic excitation in which hundreds of action potentials (APs), evoked over several seconds, eventually initiate spontaneous AP firing that sometimes lasts for minutes (Sheffield et al., 2011). BF is different from other forms of persistent firing (Egorov et al., 2002; Major and Tank, 2004; Fransen etal., 2006; Thuault etal., 2013) because it is restricted to inhibitory interneurons and the APs appear to be initiated in the distal axon. The induction mechanism for $\mathrm{BF}$ is unclear, but it might involve accumulation of extracellular $\mathrm{K}^{+}$, changes in $\mathrm{Ca}^{2+}$ signaling, or intercellular communication via gap junctions (Sheffield et al., 2011, 2013). BF has been reported to occur in a subclass of interneurons of the hippocampus and neocortex (Sheffield etal., 2011, 2013) and in neurogliaform (NG) and fast-spiking (FS) interneurons of the hippocampus (KrookMagnuson et al., 2011). However, none of these studies directly tested hypotheses about the possible functions of this type of activity.

In this paper we examine the possibility that $\mathrm{BF}$ is a mechanism by which excess excitation initiates compensatory feedback inhibition that outlasts the original excitation. By prolonging and generalizing synaptic inhibition, BF could function as an endogenous anticonvulsant mechanism. We show that this form of firing has a number of characteristics that are compatible with such a role.

\section{MATERIALS AND METHODS ETHICAL APPROVAL}

All animal housing, breeding and surgical procedures were approved by the Animal Experimentation Ethics Committee of the Australian National University and conform to the guidelines of the National Health and Medical Research Council of Australia. 


\section{ANIMALS}

The majority of experiments used heterozygous GAD67-GFP $(\Delta$ neo) mice of either sex in which green fluorescent protein (GFP) is specifically expressed in neurons containing $\gamma$-aminobutyric acid (GABA; Tamamaki et al., 2003; Suzuki and Bekkers, 2010b). Here we use the shorthand GAD67-GFP when referring to these animals. GAD67-GFP mice are bred on a C57BL6/J background and have normal behavior and neuroanatomy (Kerlin et al., 2010; Suzuki and Bekkers, 2010b; Zhan and Luo, 2010). $\mathrm{GFP}^{+}$cells in these mice have the electrical and morphological features of normal GABAergic interneurons (Suzuki and Bekkers, 2010a). Use of GAD67-GFP mice greatly facilitated targeted recordings from inhibitory interneurons. However, some experiments used wildtype C57BL6/J mice and yielded identical results.

\section{SLICE PREPARATION}

Experiments used acute brain slices ( $300 \mu \mathrm{m}$ thick) prepared from 59 GAD67-GFP or wildtype C57BL6/J mice (18-45 d-old). Standard methods of slice preparation were used (Suzuki and Bekkers, 2010a, 2011, 2012). Briefly, mice were deeply anesthetized with isoflurane ( $2 \%$ in oxygen) then rapidly decapitated. Using a vibrating slicer (Campden Instruments), coronal slices of the cortex or transverse slices of the hippocampus were prepared under ice-cold cutting solution containing (in $\mathrm{mM}$ ) $125 \mathrm{NaCl}, 3 \mathrm{KCl}, 0.5 \mathrm{CaCl}_{2}$, $6 \mathrm{MgCl}_{2}, 25 \mathrm{NaHCO}_{3}, 1.25 \mathrm{NaH}_{2} \mathrm{PO}_{4}$, and 10 glucose (osmolarity $305 \mathrm{mOs} / \mathrm{kg}$ ), bubbled with $5 \% \mathrm{CO}_{2} / 95 \% \mathrm{O}_{2}$ (carbogen). The slices were incubated for $1 \mathrm{~h}$ at $35^{\circ} \mathrm{C}$ in a holding chamber containing carbogen-bubbled artificial cerebrospinal fluid (ACSF; composition below), then were held at room temperature until required.

\section{SURGERY FOR IN VIVO EXPERIMENTS}

These experiments used 17 GAD67-GFP mice (30-45 d-old). Animals were anesthetized with chlorprothixene $(5 \mathrm{mg} / \mathrm{kg}$ I.P.) and urethane $(0.5-1 \mathrm{~g} / \mathrm{kg}$ I.P.). When the pinch reflex was completely absent (typically after 10-20 min), animals were placed on a heating blanket to maintain physiological body temperature. An injection of a local anesthetic (prilocaine hydrochloride, $0.2 \mathrm{mg} / \mathrm{ml} \mathrm{s.C.)} \mathrm{was} \mathrm{delivered} \mathrm{to} \mathrm{the} \mathrm{scalp,} \mathrm{then} \mathrm{the} \mathrm{skin} \mathrm{over}$ the top of the head was retracted and a craniotomy performed to expose a small region $(\sim 3 \mathrm{~mm}$ diameter $)$ of the primary somatosensory cortex. The dura mater was left intact. Depth of anesthesia was monitored frequently using the pinch reflex test. A top-up dose of urethane (half the initial dose) was typically required $4-6 \mathrm{~h}$ after the start of surgery. Saline (100-200 $\mu \mathrm{l}$ I.P.) was administered every hour to maintain hydration. At the end of the experiment the animal was killed by an overdose of urethane and decapitation without being allowed to regain consciousness.

\section{SLICE ELECTROPHYSIOLOGY}

Infrared-differential interference contrast videomicroscopy was used to make visualized whole-cell patch clamp recordings from $\mathrm{GFP}^{+}$neurons in anterior piriform cortex, primary somatosensory cortex and area CA1 of the hippocampus, or from $\mathrm{GFP}^{-}$ glutamatergic principal neurons in layer 2 of the piriform cortex.
The different classes of piriform cortex GABAergic interneurons were identified by their characteristic electrical properties, morphologies and laminar location, as previously described (Suzuki and Bekkers, 2010a,b). NG cells were initially identified by their very bright GFP fluorescence, and FS cells by their larger and more weakly fluorescent somata located in layer 3. The identities of both cell types were subsequently confirmed by their intrinsic electrical properties and morphologies (Suzuki and Bekkers, 2010a).

Slices were continuously superfused (2-3 ml/min) with ACSF containing (mM) $125 \mathrm{NaCl}, 3 \mathrm{KCl}, 2 \mathrm{CaCl}_{2}, 1 \mathrm{MgCl}_{2}, 25 \mathrm{NaHCO}_{3}$, $1.25 \mathrm{NaH}_{2} \mathrm{PO}_{4}$, and 25 glucose $(310 \mathrm{mOs} / \mathrm{kg})$, bubbled with $5 \%$ $\mathrm{CO}_{2} / 95 \% \mathrm{O}_{2}$ (carbogen) and maintained at $33-35^{\circ} \mathrm{C}$. In some experiments (Figure 5) the concentration of $\mathrm{KCl}$ in the ACSF was raised to $7 \mathrm{mM}$ or $9 \mathrm{mM}$. For current clamp recordings, patch electrodes had resistances of 6-10 $\mathrm{M} \Omega$ when filled with internal solution containing (mM) $135 \mathrm{KMeSO}_{4}, 7 \mathrm{NaCl}, 0.1$ EGTA, $2 \mathrm{Na}_{2} \mathrm{ATP}, 2 \mathrm{MgCl}_{2}, 0.3 \mathrm{GTP}, 10$ HEPES at pH 7.2, supplemented with $0.2-0.4 \%$ biocytin $(295-300 \mathrm{mOs} / \mathrm{kg})$. This solution had a $\mathrm{Cl}^{-}$concentration of $11 \mathrm{mM}$ and a measured junction potential of $-7 \mathrm{mV}$. For voltage clamp recordings (e.g., Figure 6), $135 \mathrm{mM} \mathrm{CsCl}$ replaced the $\mathrm{KMeSO}_{4}$ (giving a junction potential of $0 \mathrm{mV}$ ) and electrodes had resistances of 5-7 M $\Omega$. The presence of $\mathrm{Cs}$ in this internal solution blocked the $\mathrm{K}$ channels that mediate the $\mathrm{GABA}_{\mathrm{B}}$ response. The holding potential was $-90 \mathrm{mV}$. All voltages given in this paper are corrected for junction potentials. Unless stated otherwise, all compounds were obtained from Sigma-Aldrich.

Neurons were visualized using a BX51WI microscope with a $40 \times / 0.8$ NA objective (Olympus). Electrical data were acquired using a Multiclamp 700A amplifier (Molecular Devices). For current clamp recordings, the cell was allowed to remain at its resting membrane potential. Bridge balance and capacitance neutralization were carefully adjusted and checked for stability. For voltage clamp recordings, series resistance was monitored for stability but series resistance compensation was not used. Voltage or current traces were filtered at $10 \mathrm{kHz}$ and digitized at 20 or $50 \mathrm{kHz}$ by an ITC-18 interface (Instrutech/HEKA) under the control of Axograph (Axograph Scientific).

Focal extracellular synaptic stimulation (e.g., Figure 5A) was done using a custom-built isolated stimulator that delivered a $100 \mu$ s-long constant current pulse with an adjustable amplitude. The stimulating electrode was constructed from a patch electrode (tip diameter $\sim 5 \mu \mathrm{m}$ ) filled with $1 \mathrm{M} \mathrm{NaCl}$ and coated with electrically conductive paint. The stimulus current was passed between the filling solution and a wire connected to the paint; hence, this functioned as a concentric bipolar stimulating electrode (Bekkers and Clements, 1999). The tip of the stimulating electrode was placed $200 \mu \mathrm{m}$ from the soma of the recorded cell, in the same layer, to avoid directly stimulating the axon of the cell.

Barrage firing was triggered using three types of electrical stimuli: (i) $1 \mathrm{~s}$-long depolarizing current steps (0.5-1.5 nA) applied via the somatic electrode at $0.5 \mathrm{~Hz}$; each step elicited trains of 20-60 APs in NG cells (e.g., Figure 1D) or 100-160 APs in FS cells (e.g., Figure 3D). (ii) 2 ms-long depolarizing current steps (1.0-1.5 nA) applied at the soma at $20 \mathrm{~Hz}$; each step elicited a single AP (e.g., Figure 2A). (iii) A train of extracellular synaptic 


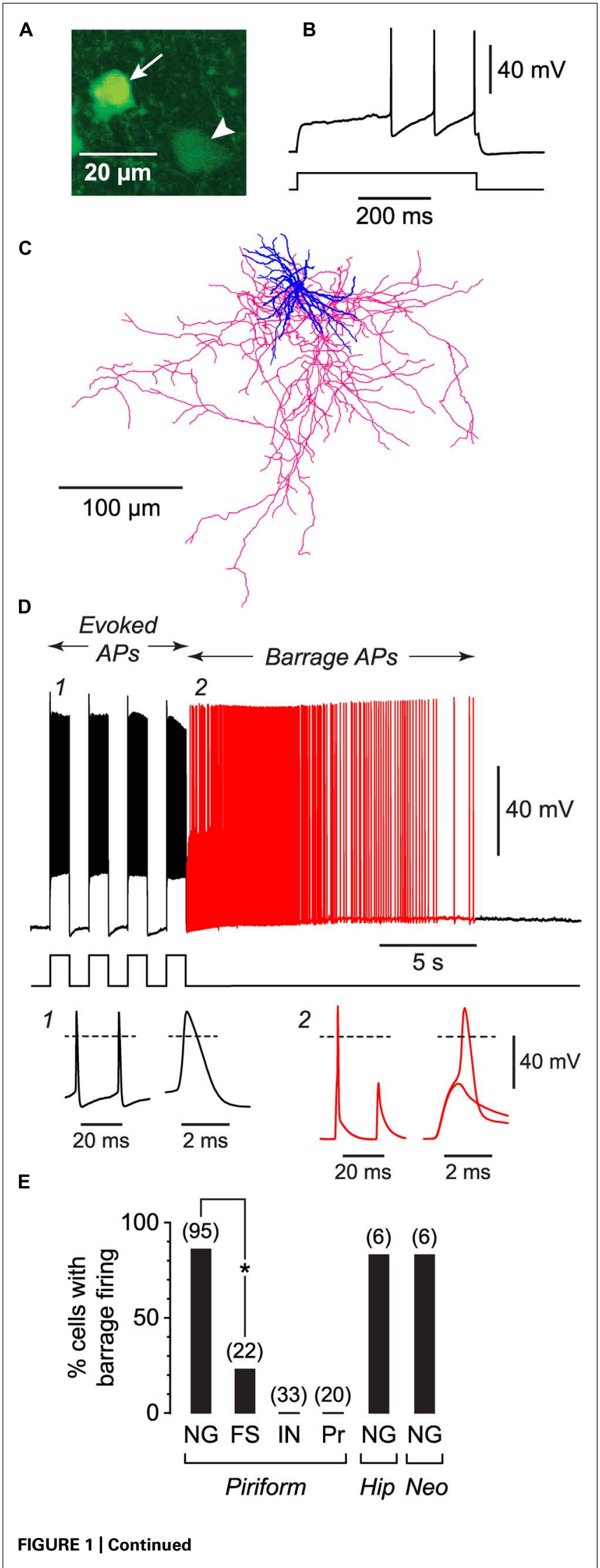

\section{FIGURE 1 | Continued}

NG cells preferentially exhibit persistent barrage firing. All data shown in this figure were obtained from acute brain slices. (A), Fluorescence image of a region in layer 3 of the piriform cortex from a GAD67-GFP mouse, showing the bright GFP fluorescence in the soma of a NG cell (arrow) compared with the weak GFP fluorescence in a nearby non-NG cell (arrowhead). (B), Response of the arrowed NG cell in (A) to a depolarizing current step $(220 \mathrm{pA})$ just above rheobase. Note the delay to spiking, characteristic of NG cells. (C), Tracing of the same cell as in (A), showing the dense arbor of dendrites (blue) and axons (red) typical of NG cells (Suzuki and Bekkers, 2010a). (D), Induction of BF in the same cell as in (A). Induction comprised a series of depolarizing 800 pA current steps (shown below) that were ceased when BF commenced (red part of trace). Insets, bottom, show action potentials at the numbered locations in the main panel, displayed on two different time scales. Note the spikelet (small amplitude AP) in inset 2. The spikelet and full-height spike in this inset are shown superimposed on an expanded timebase on the right, showing that the full-height spike appears to ride on the back of a spikelet. Dashed lines, $0 \mathrm{mV}$. (E), Percentage of cells showing BF for different types of neurons. FS, fast-spiking; IN, other interneuron types in the piriform cortex (regular-spiking, horizontal, bitufted); Pr, layer 2 principal cells; Hip, hippocampus (CA1 Stratum lacunosum-moleculare); Neo, somatosensory neocortex (layers 1-3). Number of induction attempts is given in parentheses. Asterisk, significantly different $\left(p=2 \times 10^{-6}\right.$, Fisher's exact test).

stimuli applied at $20 \mathrm{~Hz}$; each stimulus elicited an excitatory postsynaptic potential that was suprathreshold for firing a single AP (e.g., Figure 5A). Shortly after BF emerged, the stimulus was stopped and data acquisition continued for as long as the spontaneous firing lasted. If BF did not appear after $80 \mathrm{~s}$ of continuous stimulation, the stimulus was stopped for $2 \mathrm{~min}$, then another train of up to $80 \mathrm{~s}$ duration was applied. If BF did not appear after three such trains, the cell was noted as being unable to generate this form of firing. In some experiments, $\mathrm{BF}$ was triggered by perfusing the bath with modified ACSF (Figures 5B,C).

At the conclusion of the experiment, the patch electrode was carefully retracted while maintaining the seal. The slice was fixed for $1 \mathrm{~h}$ in $4 \%$ paraformaldehyde in phosphate buffer then stored in phosphate buffer at $4^{\circ} \mathrm{C}$ until processing. Fluorescence images (e.g., Figure 1A) were obtained using a Zeiss Pascal confocal microscope with a $20 \times / 0.75 \mathrm{NA}$ objective. Image projections were made from a series of $4-10$ frames at $5 \mu \mathrm{m}$ intervals.

\section{IN VIVO ELECTROPHYSIOLOGY}

A two-photon microscope (Sutter MOM) was used to make targeted whole-cell patch clamp recordings from identified $\mathrm{GFP}^{+}$ interneurons in the upper $\sim 200 \mu \mathrm{m}$ (layers 1 and 2/3) of the primary somatosensory cortex of mice. Imaging was performed using a Chameleon Ultra Ti:Sapphire laser (Coherent) operating at $800 \mathrm{~nm}$ and a $40 \times / 0.8 \mathrm{NA}$ objective (Olympus). The mouse was placed on an electrically heated blanket to maintain a physiological core temperature, and its head was secured via a metal rod attached to the skull with dental cement. A small chamber was constructed around the craniotomy and filled with saline. The reference electrode was a chlorided silver wire inserted under the skin of the neck.

Patch electrodes and the internal solution were the same as those used in the slice current clamp experiments, except that the internal solution also contained Alexa $594(20 \mu \mathrm{M}$, 

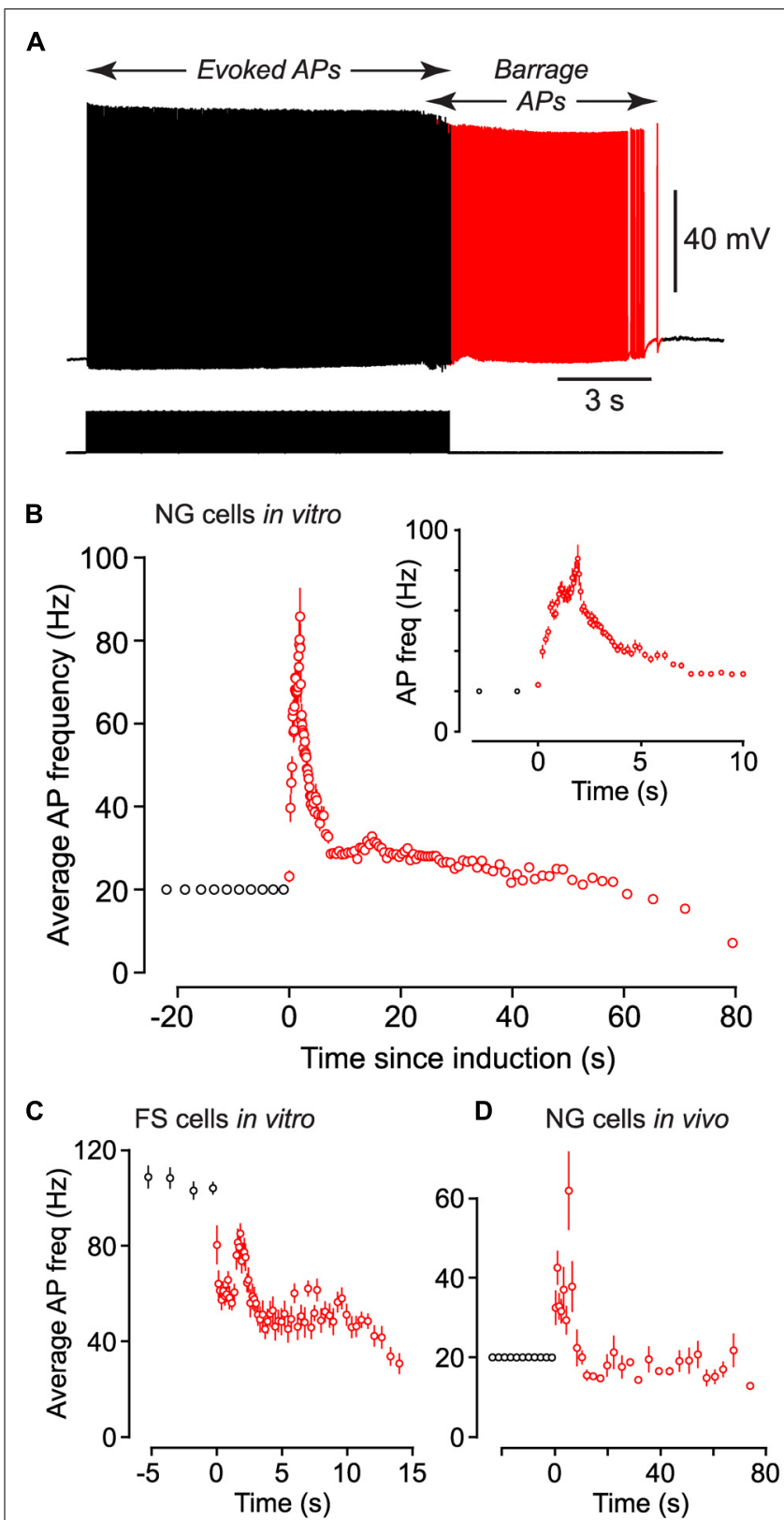

FIGURE 2 | Following induction of BF (both in vivo and in vitro) the average firing frequency of persistent APs shows characteristic changes. (A), Example of raw data from a NG cell in an acute brain slice, showing BF induced by a $20 \mathrm{~Hz}$ train of depolarizing current steps (each $1.4 \mathrm{nA}$ for $2 \mathrm{~ms}$; stimulus pattern at bottom). Red portion of trace indicates period of BF. (B), Average frequency of APs measured in $n=27 \mathrm{NG}$ cells plotted against time since induction of BF. Induction used a $20 \mathrm{~Hz}$ train of depolarizing current steps (1-1.5 nA for $2 \mathrm{~ms}$ ). Black and red symbols represent average AP frequency during the induction and BF periods, respectively. Error bars indicate $\pm S E$. Note that the time for induction of $B F$ varied between $\sim 8$ and $\sim 38 \mathrm{~s}$ in different cells. Inset shows part of the same plot expanded horizontally. (C), A similar plot of average AP frequency against time for $n=3$ FS cells recorded in acute slices of the piriform cortex. BF in these experiments was triggered by $1 \mathrm{~s}$-long depolarizing current steps repeated at $1 \mathrm{~Hz}$. (D), A similar plot of AP frequency versus time for $n=12 \mathrm{NG}$ cells recorded in vivo from the somatosensory cortex of anesthetized mice, following induction by a $20 \mathrm{~Hz}$ train of 2 ms-long depolarizing current steps.

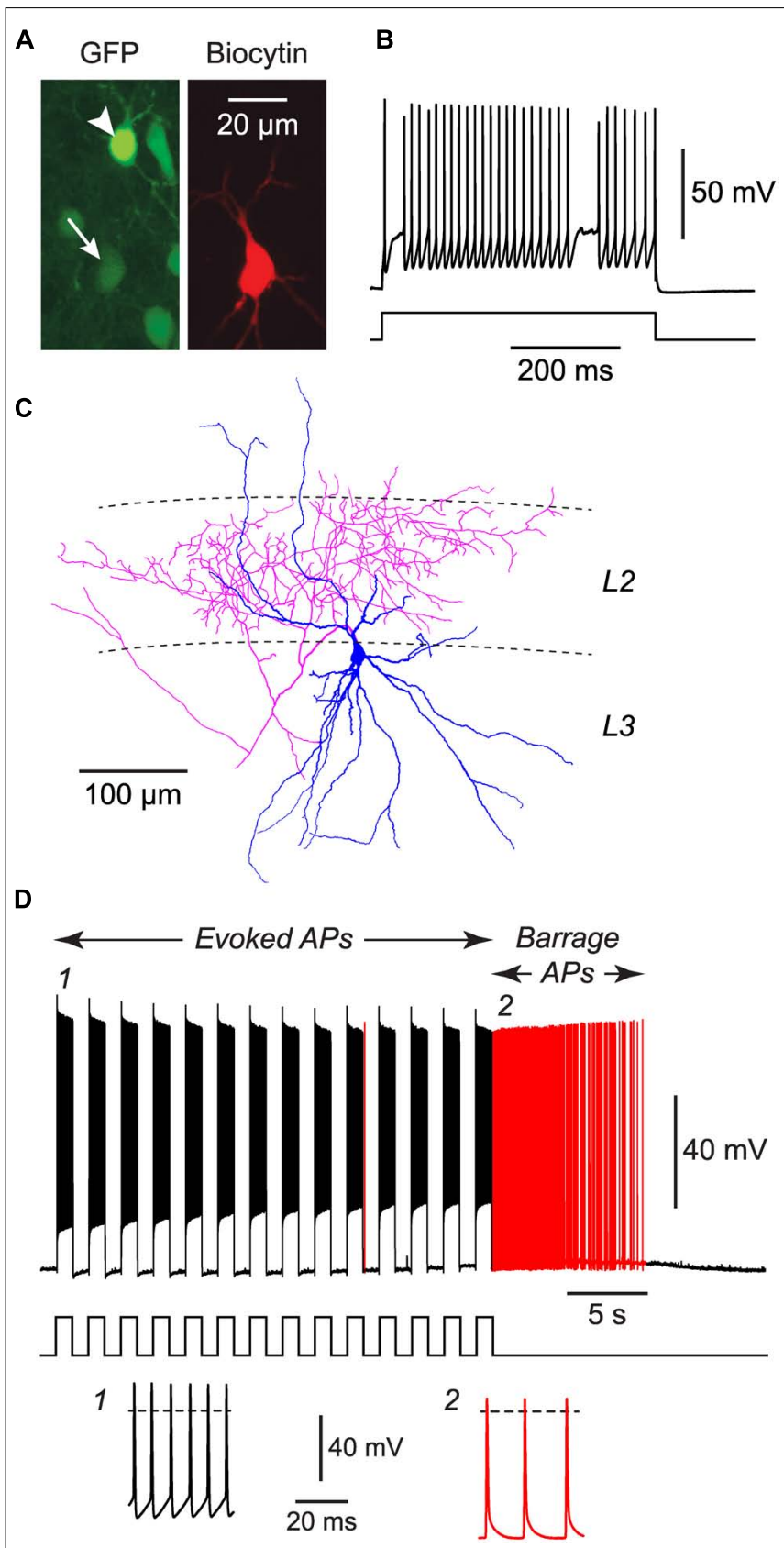

FIGURE 3 | FS cells in acute slices of the piriform cortex can also exhibit BF. (A), Fluorescence images of the same region of a slice of piriform cortex, showing GFP label in this GAD67-GFP mouse (left) and the biocytin fill of the neuron from which recordings were made (middle). The recorded FS cell has weak GFP fluorescence (arrow, bottom), contrasting with strong GFP fluorescence in a nearby NG cell (arrowhead, top). (B), Response of the filled FS cell in (A) to a current step (680 pA), showing its fast-spiking phenotype. (C), Tracing of the same cell as in (A), showing the multipolar dendrites (blue) and dense axonal projections (red) to layer 2 (L2) that are typical of FS cells in the piriform cortex (Suzuki and Bekkers,

2010a). (D), Response of the cell in panels (A-C) to a series of current steps ( $1 \mathrm{nA}$ for $1 \mathrm{~s}$, repeated at $0.5 \mathrm{~Hz}$ ) that eventually elicited BF (red portion of trace). Stimulus pattern is shown at bottom. Insets, bottom, show action potentials at the numbered locations in the main panel. Dashed lines, $0 \mathrm{mV}$. 


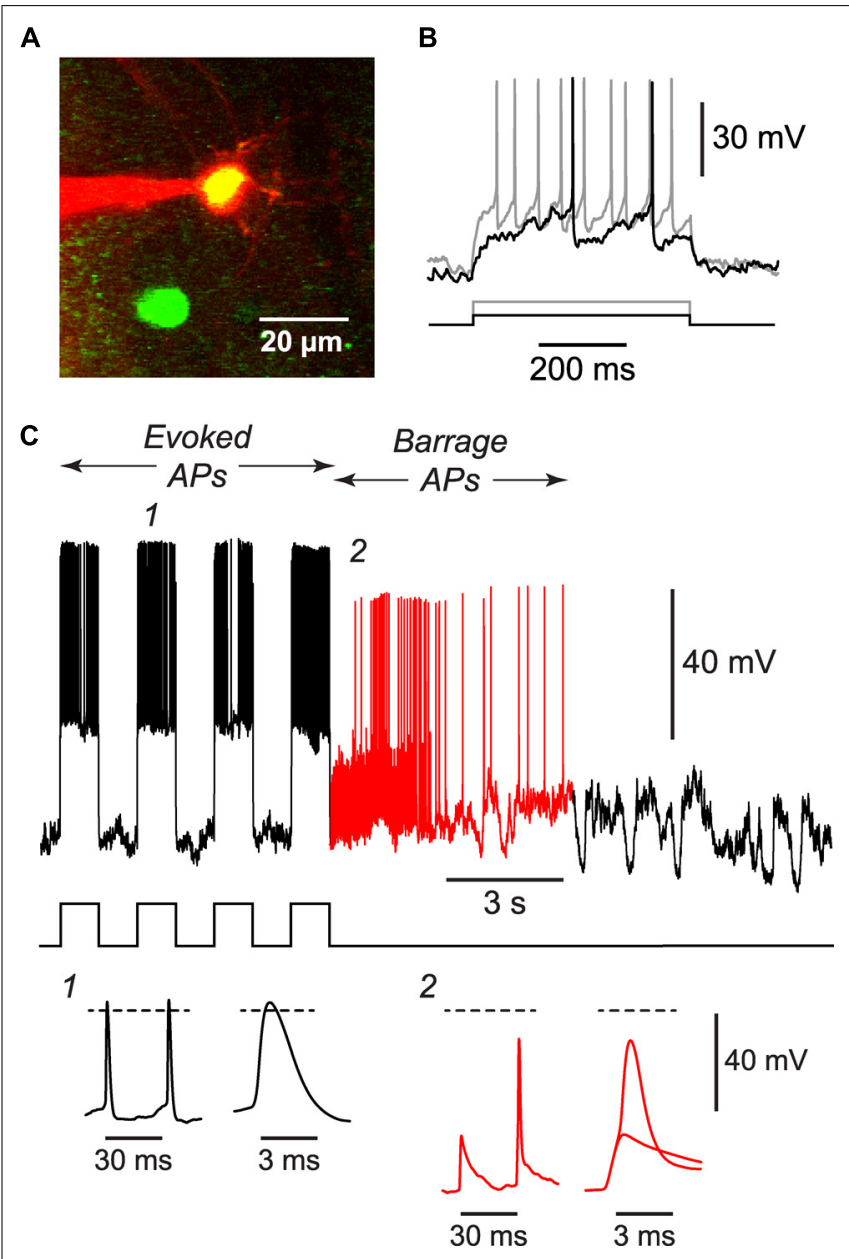

FIGURE 4 | BF can be induced in NG cells in vivo. (A), 2-photon microscope image showing a whole-cell patch electrode (red) on a NG cell in upper layer 2 of the somatosensory cortex of an anesthetized GAD67-GFP mouse. This image is a merge of two z-projections, one (green) showing GFP, the other (red) showing the Alexa 594 dye in the solution in the patch electrode. (B), Responses of the cell in (A) to depolarizing current steps (black, 50 pA; gray, 120 pA) showing the delayed firing and lack of accommodation typical of NG cells. (C), Example of the $\mathrm{BF}$ induced by a train of current steps $(240 \mathrm{pA}$ for $1 \mathrm{~s}$; stimulus pattern at bottom) in the NG cell shown in panels $(\mathbf{A}, \mathbf{B})$. Red portion of trace indicates period of BF. Insets, bottom, show action potentials at the numbered locations in the main panel, displayed on two different time scales. The spikelet and full-height spike in inset 2 are shown superimposed on an expanded timebase on the right. Dashed lines, $0 \mathrm{mV}$. Elevated electrode resistance attenuated the AP amplitudes in this experiment, and difficulties in adjusting the bridge balance accounts for the apparent larger peak amplitude of evoked APs (see Materials and Methods).

Invitrogen) to enable visualization of the electrode in the red channel (Figure 4A). Putative NG cells were identified by their very bright fluorescence in the green channel (Figure 4A). A patch electrode was advanced through the dura mater while applying high pressure $(25 \mathrm{kPa})$ to the back of the electrode, then the pressure was reduced $(6-8 \mathrm{kPa})$ and a targeted whole-cell recording was obtained in the usual way. Electrode series resistance was higher than is typical in the acute slice preparation; hence, the bridge balance was difficult to adjust accurately, and APs were often attenuated and sometimes did not overshoot $0 \mathrm{mV}$ (e.g., Figure 4C). However, by all other criteria (e.g., resting membrane potential, input resistance, cell morphology) the neurons were healthy. BF was induced by a series of 1 s-long depolarizing current steps (200-500 pA) applied via the patch electrode at $0.5 \mathrm{~Hz}$. At the end of the experiment an image stack was acquired in the red channel (10 $\mu \mathrm{m}$ interval) to document the dendritic arbor of the cell. In some experiments the animal was perfused with $4 \%$ paraformaldehyde and the morphology of the cell was recovered.

\section{ANALYSIS}

Neuronal morphology (e.g., Figure 1C) was revealed using an ABC kit (Vector Laboratories) and diaminobenzidine, or by labeling with streptavidin-Alexa 594 (Invitrogen; e.g., Figure 3A). Cell tracing was done manually using the Neurolucida tracing system (MBF Bioscience). All electrophysiological analysis was done using either Axograph or Igor Pro (Wavemetrics). For the "1 s steps" induction protocol (1 s-long current steps repeated at $0.5 \mathrm{~Hz}$; e.g., Figure 1D; Table 1), average AP frequency during induction was calculated only for the periods of current injection. When measuring the instantaneous AP frequency with respect to BF onset (Figures 2B-D), any stimulus-evoked APs occurring after onset were disregarded. Spikelets as well as full-height APs were counted for this analysis. The plots in Figures 2B-D were obtained by combining instantaneous frequency data from all cells then averaging over successive time windows, whereas the average peak frequencies given in Table 1 were found by averaging the individual peak frequencies found for each cell. The mean voltage threshold, rise time and peak of APs during induction ("Induct") and of barrage-firing APs ("BF"), given in Table 1, were calculated either by averaging five consecutive APs near the start of induction (for "Induct" data) or by averaging the first five spontaneous APs after the start of BF (for "BF" data). AP voltage threshold was measured as the membrane potential $\left(V_{m}\right)$ at which $d V_{m} / d t$ first exceeded $50 \mathrm{mVms}^{-1}$. AP risetime was the time between the voltage threshold and the peak of the AP. All errors represent \pm standard error (SE), with $n$ the number of cells. Statistical tests used Fisher's exact test or ANOVA, as indicated, or the paired or unpaired $t$-test if not explicitly stated.

\section{RESULTS}

\section{ONLY TWO CLASSES OF INTERNEURONS IN THE PIRIFORM CORTEX EXHIBIT BARRAGE FIRING}

We began by making whole-cell recordings from neurons in acute slices from the anterior piriform cortex, which is known to be highly epileptogenic (Piredda and Gale, 1985). For these initial experiments, slices were prepared from young (18-25 d-old) mice. We took advantage of our earlier work classifying the different subtypes of GABAergic interneurons in the piriform cortex (Suzuki and Bekkers, 2010a) to record from specific classes of interneurons. For example, NG interneurons were identified by their compact dendritic morphology (Price et al., 2005; Figure 1C), very bright expression of GFP in tissue from GAD67-GFP mice (Suzuki and Bekkers, 2010a; Figure 1A), and distinctive delay to firing close to threshold (Capogna and Pearce, 2011; Figure 1B). For each neuron we attempted to induce BF by applying depolarizing current steps to elicit trains of evoked APs. Two types of current 


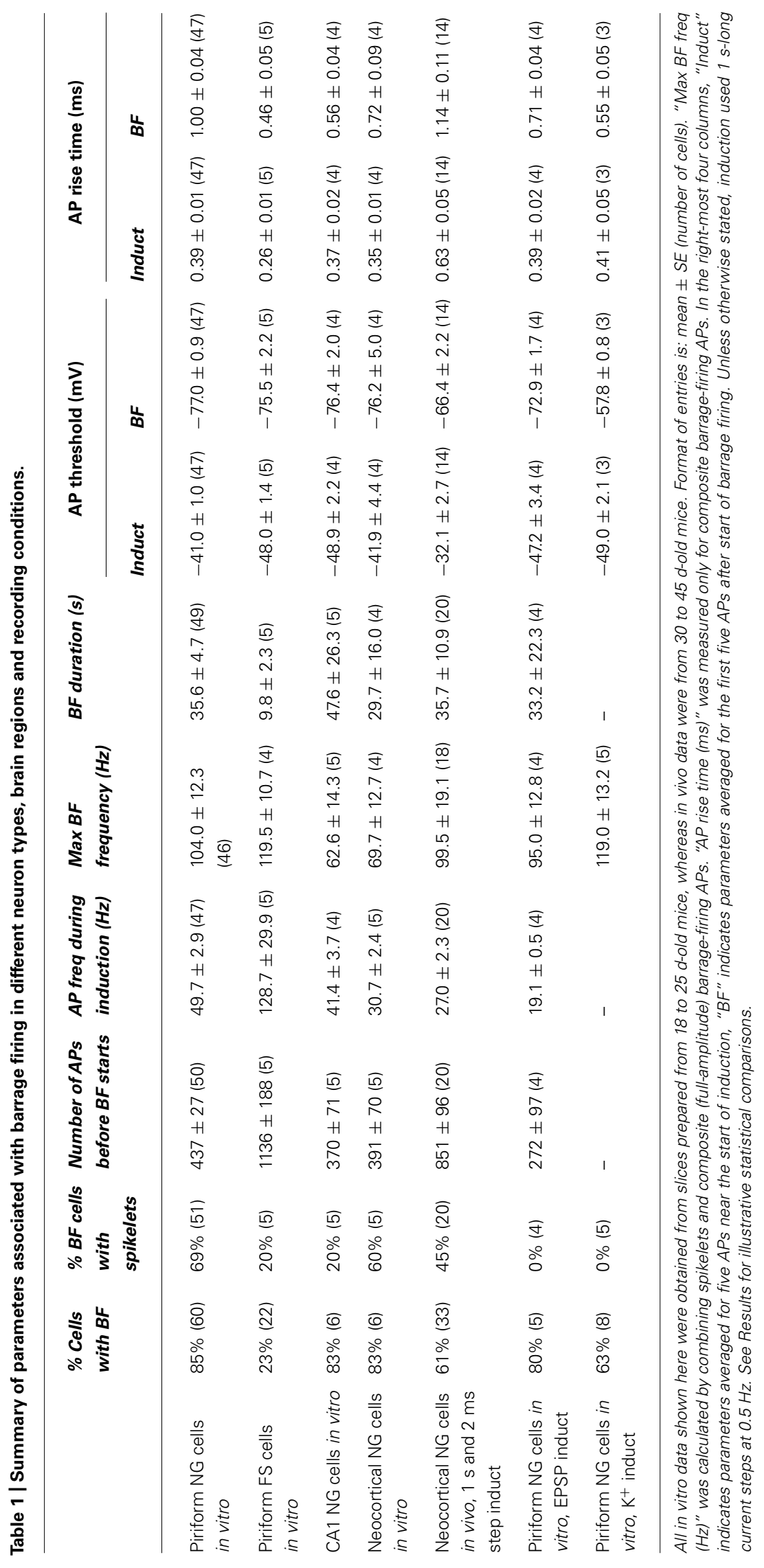


step patterns were used: $1 \mathrm{~s}$-long steps at $0.5 \mathrm{~Hz}$ (Figure 1D) and $2 \mathrm{~ms}$-long steps at $20 \mathrm{~Hz}$ (Figure 2A). BF, when present, typically emerged after 5-20 s of stimulation (e.g., Figure 1D). We scored cells as being unable to generate this form of firing if it did not emerge after three trains of stimulation, each lasting $80 \mathrm{~s}$.

Barrage firing was very common in NG cells in all layers of the piriform cortex ( $86 \%$ of cells with both induction protocols; $n=95$; Figure 1E). Using the $1 \mathrm{~s}$ step induction protocol, $\mathrm{BF}$ required $437 \pm 27$ evoked $\mathrm{APs}$ for its emergence, and it lasted $35.6 \pm 4.7 \mathrm{~s}$ (mean \pm SE, $n=47-49$; Table 1). Similar results were obtained for the $2 \mathrm{~ms}$ step induction protocol $(452 \pm 38$ APs; $27.0 \pm 5.9$ s duration; $n=28$; not significantly different from $1 \mathrm{~s}$ step induction, $p>0.7$ ). In agreement with previous work (Sheffield et al., 2011, 2013), barrage-firing APs had a dramatically hyperpolarized voltage threshold (significantly different from regular APs, $p<0.01$, ANOVA; Table 1; Figure 1D, insets 1, 2). Isolated barrage-firing spikelets were frequently seen (Figure 1D, inset 2), occurring in 69\% of NG cells that expressed this kind of firing (Table 1). Full-height barrage-firing APs appeared to comprise an initial spikelet upon which rode an AP of normal amplitude (Figure 1D, inset 2 with expanded time scale). The resulting inflection in the rising phase of full-height barrage-firing APs gave them a significantly slower rise time compared with normal APs $(p<0.01$, ANOVA; Table 1).

All of these properties are consistent with barrage spike initiation in the distal axon (Sheffield et al., 2011, 2013). It is thought that barrage-firing spikes propagate retroaxonally toward the soma, appearing there as attenuated spikelets that rise from a strongly hyperpolarized voltage threshold (Figure 1D, inset 2). A spikelet may or may not trigger a full-amplitude perisomatic spike (Figure 1D, inset 2). That is, the critical feature of a barrage-firing spike is its hyperpolarized voltage threshold, not its amplitude, which might be small (for a spikelet alone) or large (for a composite AP made up of a spikelet and a perisomatic spike). Unless otherwise stated (legend to Table 1), our analysis of BF treated spikelets and composite APs equivalently.

Barrage-firing APs exhibited stereotyped changes in firing frequency after their induction. Following the induction of this form of firing in NG cells by a train of 2 ms-long current steps at $20 \mathrm{~Hz}$, the average firing frequency of APs rose to a peak of $91.8 \pm 11.1 \mathrm{~Hz}$ after $1.65 \pm 0.24 \mathrm{~s}(n=27)$ then gradually declined (Figures 2A,B; note the slightly lower peak frequency in this figure due to the different analysis method; Materials and Methods).

We performed similar experiments in FS cells in the piriform cortex, identified in GAD67-GFP mice by their GFP fluorescence, morphology and electrical properties (Suzuki and Bekkers, 2010a; Figures $3 \mathrm{~A}-\mathrm{C}$ ). BF was also present but much less common in FS cells $(23 \%, n=22 ; p<0.01$ compared with NG cells, Fisher's exact test; Figure 1E). BF in FS cells was similar to that in NG cells. For example, hyperpolarized spikelets were also seen in FS cells (Table 1), and the mean BF frequency also showed a peak following cessation of the triggering stimulus (although the frequency of APs during BF was generally lower than that of APs during the induction phase; Figure 2C). However, BF in FS cells required 2-3 times as many evoked APs for its induction, compared with NG cells, and its duration was about one third as long (Table 1). Thus, by several measures, BF is more reluctant in FS cells.

The frequency of occurrence of BF was as common in NG cells in the somatosensory cortex $(83 \% ; n=6$; layers $1-3)$ and in the CA1 region of the hippocampus $(83 \% ; n=6$; Stratum lacunosummoleculare) as it was in NG cells in the piriform cortex $(85 \%$; $p>0.1$, ANOVA; layers 1-3; Figure 1E; Table 1). However, BF was never seen in any other class of interneuron in the piriform cortex $(n=33)$ or in layer 2 principal cells $(n=20)$ (Figure 1E).

\section{BARRAGE FIRING CAN ALSO BE INDUCED IN NG CELLS IN VIVO}

If $\mathrm{BF}$ is physiologically important, it should also occur in vivo. We tested this idea by using a two-photon microscope to make targeted whole-cell recordings from visualized NG cells in layers 1 and $2 / 3$ of the somatosensory cortex of 30-45 d-old urethaneanesthetized mice (Figure 4A). Putative NG cells were initially identified by their very bright GFP fluorescence in GAD67-GFP mice (Suzuki and Bekkers, 2010a). After achieving a whole-cell recording from one of these cells, depolarizing current steps often revealed the delay to firing near rheobase that is characteristic of NG cells (Figure 4B; Suzuki and Bekkers, 2010a), although this behavior could be ambiguous in the presence of the prominent synaptic activity that is often seen in vivo (London et al., 2010). Finally, at the end of the experiment, an image stack of the cell was acquired to confirm that it had the finecaliber, aspiny, multipolar dendritic arbor typical of NG cells (Figure 4A).

Using the $1 \mathrm{~s}$ step induction protocol, BF could be induced in a subset of NG cells in vivo $(61 \%, n=33$; Table 1). This was a smaller percentage than for the corresponding cells in vitro (83\%), and induction required about twice the number of APs $(851 \pm 96$, $n=20$; cf. $391 \pm 70, n=4$; significantly different, $p<0.001)$. Otherwise, the properties of $\mathrm{BF}$ in vivo were similar to those in vitro (Table 1; Figure 4C), after allowing for the distorting effect of the higher electrode series resistance in vivo (Methods). For example, the AP threshold in vivo was significantly hyperpolarized in barrage-firing APs compared with regular APs ( $p<0.001$; Table 1), and barrage-firing AP frequency peaked soon after induction, just as was seen in slices (Figure 2D; Table 1). Furthermore, when a full-height barrage AP occurred in vivo, it always rode on top of a spikelet (Figure 4C, insets) and had a significantly slower rise time than control APs ( $p=0.001$, paired $t$-test; Table 1$)$. These findings again implicate a distal axonal initiation site for $\mathrm{BF}$ in vivo.

Despite these similarities between slices and intact tissue, it appears that $\mathrm{BF}$ is less common and more difficult to trigger in NG cells in vivo (Table 1). A possible explanation is that in vivo experiments used older animals (40-45 d-old $c f$. 18-25 d-old for slices) and the ability to trigger BF might decline with age. This was examined by repeating the slice experiments with 40-45 d-old mice. The properties of BF were found to be similar in slices from younger and older mice (piriform NG cells from 40 to 45 d-old mice: $86 \%$ exhibited BF, $326 \pm 34$ APs before BF start $[p=0.04$ compared with 18-25 d-old mice], BF duration, $48.4 \pm 13.3 \mathrm{~s}$ [ $p=0.6], n=6$ cells; neocortical NG cells from 40 to 45 d-old mice: $100 \%$ exhibited BF, $588 \pm 26$ APs before BF start [ $p=0.06$ ], BF duration, $30.2 \pm 12.0 \mathrm{~s}[p=0.98], n=7$ cells $)$. 
In summary, BF can be induced in cortical NG cells in vivo but is less commonly observed and more difficult to initiate than in slices, for reasons that are unclear. Nevertheless, its ability to be induced in vivo suggests that it may play an important physiological role.

\section{BARRAGE FIRING CAN BE TRIGGERED UNDER CONDITIONS OF HYPEREXCITABILITY}

We hypothesized that NG cells might integrate recurrent excitation in the cortex, eventually causing these cells to fire persistently and produce lasting inhibition of overactive circuits. This idea is consistent with the report that GABA released by NG cells spills out of the synaptic cleft, providing diffuse, or tonic inhibition (Olah et al., 2009; Karayannis et al., 2010; Capogna and Pearce, 2011; Fishell and Rudy, 2011). We tested this hypothesis in two ways.

First, we confirmed that BF could be triggered by patterns of activity resembling those that occur during seizures. For example, a $20 \mathrm{~Hz}$ train of excitatory synaptic stimulation was also effective at inducing BF in NG cells, like the direct current injection used above (Figure 5A $c f$. Figure 1E; $80 \%$ of synaptically excited cells exhibited BF; see Table 1 for other parameters). Moreover, BF was readily triggered in NG cells in slices made hyperexcitable by blocking synaptic inhibition or raising the extracellular $\mathrm{K}^{+}$concentration (manipulations commonly used in in vitro models of epilepsy; Jensen and Yaari, 1997; Figures 5B,C; 63\% of NG cells treated in this way exhibited BF, $n=8$ cells; see Table 1 for other parameters). In some cases $(n=2)$, elevated $\mathrm{K}^{+}$caused the emergence of APs without the prior occurrence of regular, depolarization-evoked APs (Figure 5C). Interestingly, isolated spikelets were not seen in any of the experiments using elevated $\mathrm{K}^{+}$, possibly because the $\mathrm{K}^{+}$depolarization enabled spikelets to reliably trigger fullamplitude perisomatic spikes. In summary, these experiments indicate that NG cells can react to proconvulsant conditions by generating $\mathrm{BF}$.

\section{BARRAGE-FIRING NG CELLS CAN SYNAPTICALLY INHIBIT NEARBY PRINCIPAL CELLS}

As a second test of our hypothesis, we determined whether BF APs in NG cells could produce synaptic inhibition in nearby glutamatergic neurons. We made pair recordings from a connected NG cell and a layer 2 principal neuron in the piriform cortex (Figure 6). Inhibitory postsynaptic currents (IPSCs) generated by NG cells are known to depress during trains (Karayannis et al., 2010). Hence, a spike-triggered average of IPSCs in the postsynaptic pyramidal cell declined over seconds until only a pedestal of synaptic current remained (Figure 6C). Nevertheless, when BF emerged (in this example, after $\sim 10 \mathrm{~s}$ ) APs were still capable of generating a small, plateau IPSC $(7.8 \pm 2.3 \mathrm{pA}$, or $4.7 \pm 1.3 \%$ of the initial peak IPSC amplitude, $n=6$ pairs). This IPSC was blocked by an inhibitor of $\mathrm{GABA}_{\mathrm{A}}$ receptors $(100 \mu \mathrm{M}$ picrotoxin; not illustrated). Hence, $\mathrm{BF}$ in NG cells can drive lasting synaptic inhibition in nearby pyramidal cells.

\section{DISCUSSION}

In this paper we examine further the phenomenon of persistent firing in GABAergic interneurons (Sheffield et al., 2011), more recently called retroaxonal barrage firing to distinguish it from

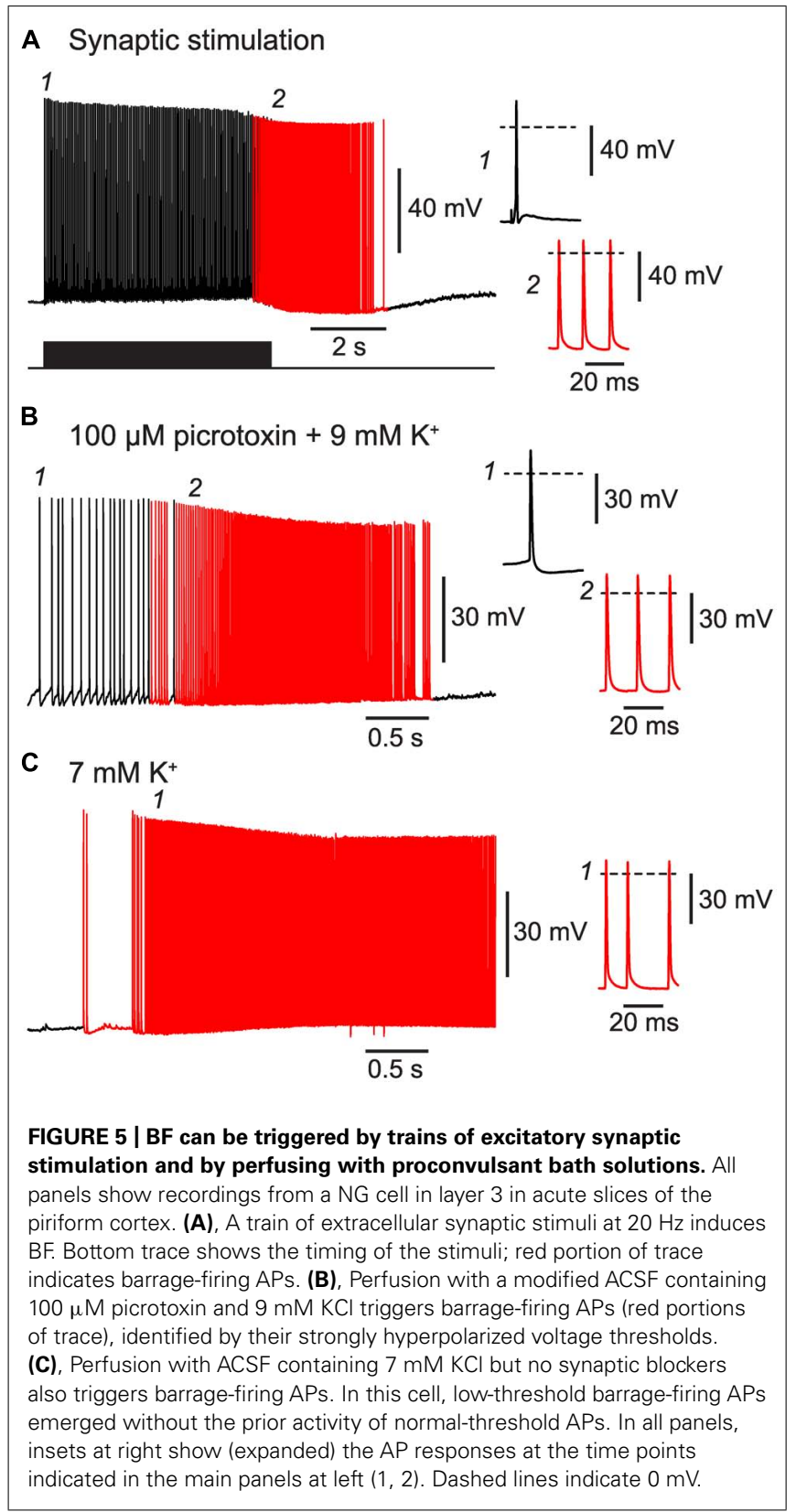

other forms of persistent firing (Major and Tank, 2004; Sheffield et al., 2013; Thuault et al., 2013). We report that BF is most commonly expressed by NG cells in the cerebral cortex and hippocampus ( $>80 \%$ in piriform cortex, somatosensory cortex and hippocampus in vitro, $\sim 60 \%$ in somatosensory cortex in vivo). A substantial minority of FS cells in the piriform cortex $(\sim 23 \%)$ also express this kind of firing, but it was never seen in any other class of interneurons or in principal neurons in the piriform cortex. We further show that BF can be induced in NG cells in the somatosensory cortex in vivo, although it appears to be more reluctant to initiate in vivo than in vitro. Our in vivo findings are, of course, subject to the usual provisos about the use of general anesthetics (Zhan and Luo, 2010). However, the induction of BF appears to be a local or cell-autonomous phenomenon 


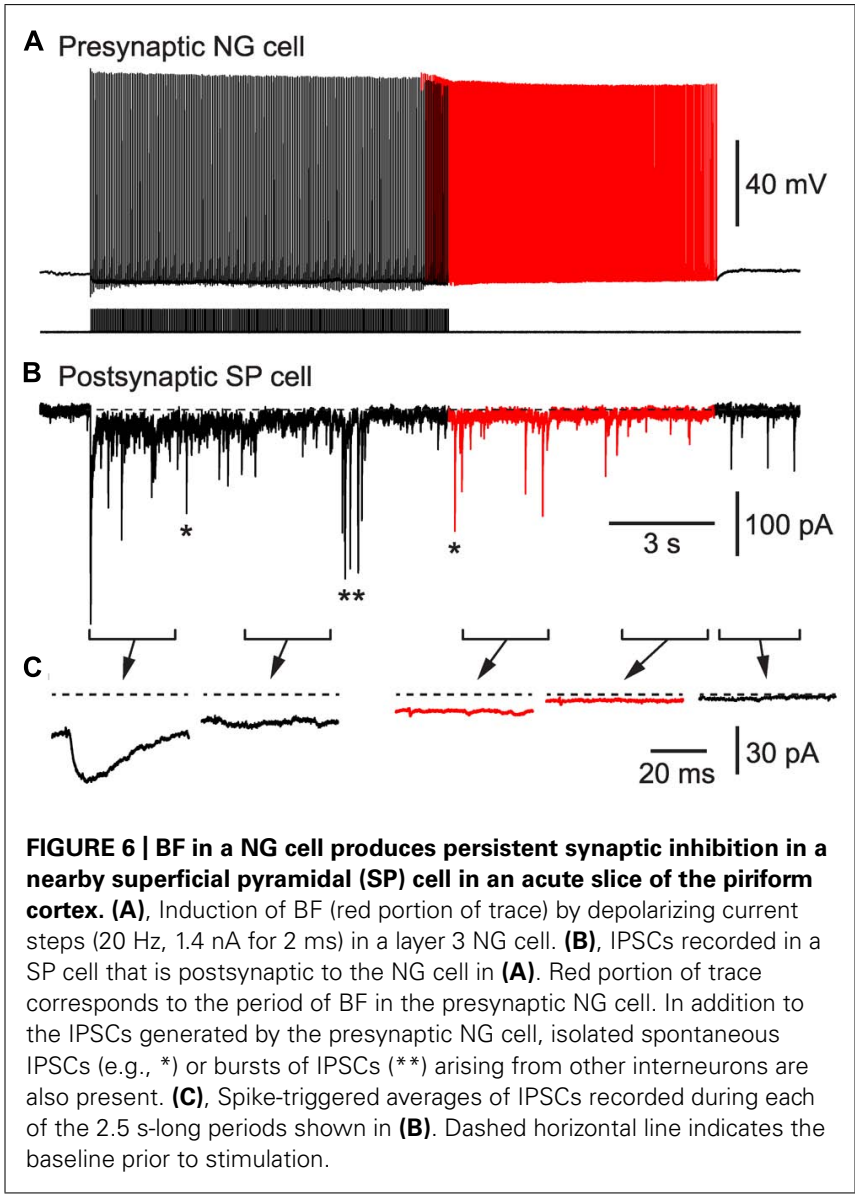

(Sheffield et al., 2011, 2013) and may therefore be less susceptible to the subtle, global modulation of network processing thought to be produced by general anesthesia (Alkire et al., 2008; Brown et al., 2011). Finally, we report that BF is triggered by manipulations that replicate the excessive excitation that occurs during seizures, and that NG cells exhibiting this behavior can synaptically inhibit nearby pyramidal cells. This leads us to propose that NG cells (and perhaps also FS cells) are equipped to monitor excitability in their local neighborhood, providing a diffuse kind of inhibition that can outlast the original stimulus. That is, we suggest that barrage-firing interneurons can provide a generalized and autonomous form of inhibition that is triggered by over-excitation (see Figure 7 and its legend for a fuller explanation of this idea).

Our findings are consistent with a recent report that $\mathrm{BF}$ is expressed by $82 \%$ of Ivy cells (a type of NG cell) and $<20 \%$ of parvalbumin-positive fast-spiking cells in the mouse hippocampus (Krook-Magnuson et al., 2011). However, our work goes further by confirming that BF occurs with similar prevalence in NG cells in the archicortex (hippocampus), paleocortex (piriform cortex) and somatosensory neocortex across a range of ages (18-45 d-old animals). Importantly, we also show that BF can be induced in the cortex in vivo, supporting the view that it is not an artifact of slice recordings and may have evolved to perform physiologically important functions. Finally, we explore a variety of
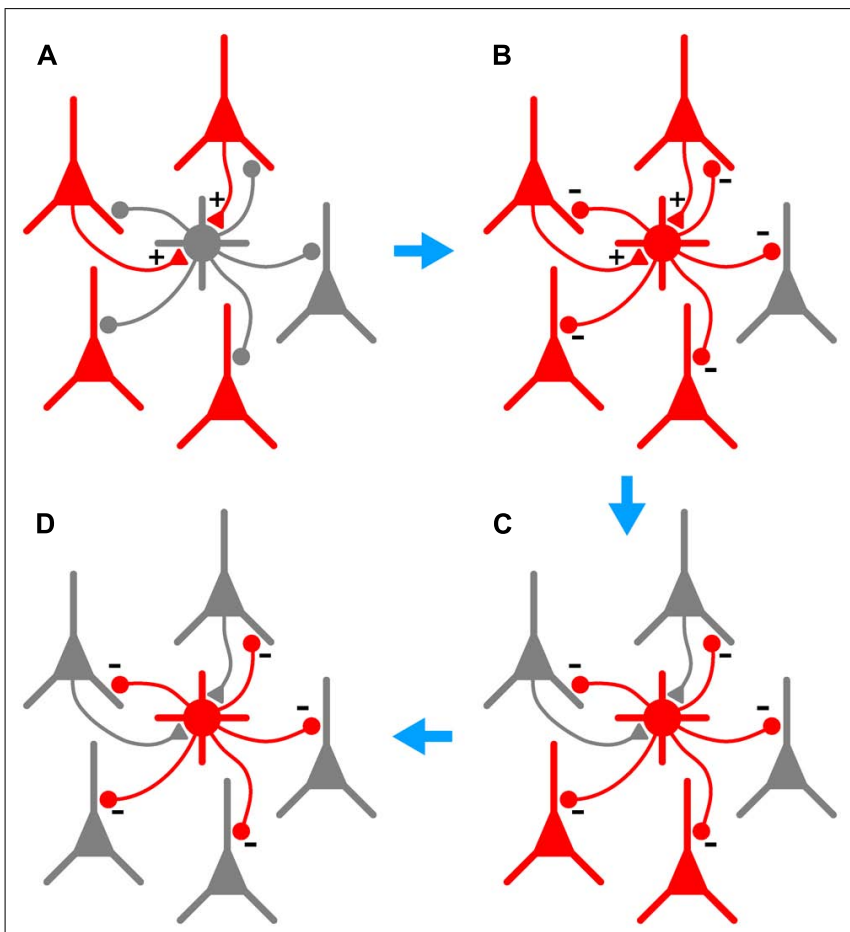

FIGURE 7 | Hypothesized series of steps by which BF could lead to autonomous and generalized inhibition in response to cortical hyperexcitability. (A), A population of pyramidal cells becomes hyperexcitable (red). A subset of these pyramidal cells synaptically excites a nearby NG or FS interneuron (+ symbols on gray cell at center). (B), As a result of this excitation, the interneuron begins to fire repeatedly (gray cell becomes red), synaptically inhibiting a large number of pyramidal cells in its vicinity (- symbols). (C), This inhibition eventually silences a subset of pyramidal cells, including those that are synaptically exciting the interneuron (upper two pyramidal cells become gray). However, BF ensures that the interneuron keeps firing after the presynaptic pyramidal cells fall silent, allowing the interneuron to continue inhibiting other nearby pyramidal cells that do not excite it. (D), In due course all hyperexcitable pyramidal cells near the interneuron are silenced (all become gray). BF in the interneuron eventually ceases (not shown). Note that the scheme depicted here would only work in the cerebral cortex; hippocampal NG cells do not provide feedback inhibition to pyramidal cells (Price etal., 2005).

manipulations by which BF can be induced (synaptic stimulation, elevated $\mathrm{K}^{+}$, network disinhibition).

Exactly how BF is triggered is currently unknown, but a number of clues have emerged. The $\mu$-opioid receptor agonist, DAMGO, has been reported to increase the number of APs required to trigger BF, possibly because of DAMGO-induced hyperpolarization (Krook-Magnuson et al., 2011). More recently it has been reported that BF may be triggered by a multicellular mechanism involving calcium signaling and gap junctions, possibly between non-neuronal cells (Sheffield et al., 2013). Our experiments do not directly address induction mechanisms, but some of our findings are illuminating. We find that BF is restricted to NG cells and FS cells in the piriform cortex, which are two cell classes that possess a dense axonal plexus (Suzuki and Bekkers, 2010a) and which also express profuse gap junctions among themselves and with other interneurons (Hestrin and Galarreta, 2005; Simon et al., 2005; Zsiros and Maccaferri, 2005; Fukuda et al., 2006). 
Thus, any mechanism for BF induction that involves gap junctions and/or ectopic interactions between dense axonal arbors would be plausible.

In addition to their tendency to fire persistently, NG cells have other properties that might suit them to providing protection against seizures. NG-like interneurons are found in many brain regions (Capogna and Pearce, 2011; Fishell and Rudy, 2011) and, at least in the piriform cortex, are distributed across all laminae (Suzuki and Bekkers, 2010a,b). Strong gap junction coupling between NG cells can help to enforce synchronized firing of many NG cells in a network (Simon et al., 2005; Zsiros and Maccaferri, 2005; Olah et al., 2007). Hence, NG cells could provide uniform protective coverage over wide regions of the cortex. NG cells also produce spillover or volume transmission (Capogna and Pearce, 2011) which potentially enables them to inhibit a large number of neuronal membranes in their vicinity, or to activate presynaptic $\mathrm{GABA}_{\mathrm{B}}$ receptors, suppressing transmitter release. $\mathrm{BF}$ and the resultant release of GABA from NG cells might enhance tonic inhibition via extrasynaptic $\mathrm{GABA}_{\mathrm{A}}$ receptors (Capogna and Pearce, 2011). Low levels of persistent inhibition might also alter the intrinsic excitability of pyramidal cells by changing their input-output gain (Mitchell and Silver, 2003). However, because GABAergic transmission from NG cells readily depresses with repeated stimulation (Karayannis et al., 2010; Figure 6), BFinduced inhibition provided by these cells will be self-limiting. The inhibitory transmission provided by FS neurons does not depress so profoundly in trains (Suzuki and Bekkers, 2010a) and so, despite their lesser expression of BF (23\% of FS cells $c f$. $\sim 60-85 \%$ of NG cells; Results), FS cells might be functionally more important in providing persistent inhibition in response to seizures. Of course, postsynaptic factors, like desensitization of $\mathrm{GABA}_{\mathrm{A}}$ receptors, might also set limits on the effectiveness of persistent GABA release (Jones and Westbrook, 1996).

Although this paper focuses on the hypothesis that BF serves to suppress epileptic activity, other possible functions of BF should not be ruled out (Sheffield et al., 2011). BF might be involved in the generation of oscillations in electrical activity that are commonly observed in the cortex, including the piriform cortex (Kay et al., 2009). Alternatively, BF might be important for storing information for short periods of time, as for working memory (Thuault et al., 2013), or it might enable a novel form of communication between neurons and glia (Sheffield et al., 2013).

Assuming that BF does play a role in seizure suppression, what might be its significance for an understanding of epilepsy? The factors determining the onset of epileptic seizures have been intensively studied and are known to be very variable, reflecting the diversity of classes of epilepsies (Harlen, 1997). In contrast, the factors that determine seizure termination have been less studied. Partly this reflects the complexity of the ictal state, during which many neuronal parameters are far from equilibrium across wide areas of the brain. A number of factors have been suggested to be important for termination, including generalized alterations in transmembrane ion gradients, changes in levels of neuromodulators and metabolites, and activation or inactivation of ion channels (see Lado and Moshe, 2008, for review). Here we propose a different idea, namely, that there are specialized inhibitory circuits with the purpose of providing a kind of global feedback inhibition in response to overexcitation; i.e., their role is to be a "safety valve" for the brain. Future work would need to test this idea using more realistic in vivo models of epilepsy, and to establish whether there is, indeed, a direct causal link between BF and the termination of seizures.

\section{ACKNOWLEDGMENT}

This work was supported by the National Health and Medical Research Council of Australia (Project Grants 1009382 and 1050832 to John M. Bekkers).

\section{REFERENCES}

Alkire, M. T., Hudetz, A. G., and Tononi, G. (2008). Consciousness and anesthesia. Science 322, 876-880. doi: 10.1126/science.1149213

Bekkers, J. M., and Clements, J. D. (1999). Quantal amplitude and quantal variance of strontium-induced asynchronous EPSCs in rat dentate granule neurons. $J$. Physiol. 516, 227-248. doi: 10.1111/j.1469-7793.1999.227aa.x

Brown, E. N., Purdon, P. L., and Van Dort, C. J. (2011). General anesthesia and altered states of arousal: a systems neuroscience analysis. Annu. Rev. Neurosci. 34, 601-628. doi: 10.1146/annurev-neuro-060909-153200

Capogna, M., and Pearce, R. A. (2011). GABAA,slow: causes and consequences. Trends Neurosci. 34, 101-112. doi: 10.1016/j.tins.2010.10.005

Egorov, A. V., Hamam, B. N., Fransen, E., Hasselmo, M. E., and Alonso, A. A. (2002). Graded persistent activity in entorhinal cortex neurons. Nature 420, 173-178. doi: $10.1038 /$ nature01171

Fishell, G., and Rudy, B. (2011). Mechanisms of inhibition within the telencephalon: "where the wild things are." Annu. Rev. Neurosci. 34, 535-567. doi: 10.1146/annurev-neuro-061010-113717

Fransen, E., Tahvildari, B., Egorov, A. V., Hasselmo, M. E., and Alonso, A. A. (2006). Mechanism of graded persistent cellular activity of entorhinal cortex layer v neurons. Neuron 49, 735-746. doi: 10.1016/j.neuron.2006.01.036

Fukuda, T., Kosaka, T., Singer, W., and Galuske, R. A. (2006). Gap junctions among dendrites of cortical GABAergic neurons establish a dense and widespread intercolumnar network. J. Neurosci. 26, 3434-3443. doi: 10.1523/JNEUROSCI.407605.2006

Harlen, J. (ed.). (1997). Diagnosis and Management of Epilepsy in Adults. Edinburgh: Scottish Intercollegiate Guidelines Network.

Hestrin, S., and Galarreta, M. (2005). Electrical synapses define networks of neocortical GABAergic neurons. Trends Neurosci. 28, 304-309. doi: 10.1016/j.tins.2005.04.001

Jensen, M. S., and Yaari, Y. (1997). Role of intrinsic burst firing, potassium accumulation, and electrical coupling in the elevated potassium model of hippocampal epilepsy. J. Neurophysiol. 77, 1224-1233.

Jones, M. V., and Westbrook, G. L. (1996). The impact of receptor desensitization on fast synaptic transmission. Trends Neurosci. 19, 96-101. doi: 10.1016/S01662236(96)80037-3

Karayannis, T., Elfant, D., Huerta-Ocampo, I., Teki, S., Scott, R. S., Rusakov, D. A., et al. (2010). Slow GABA transient and receptor desensitization shape synaptic responses evoked by hippocampal neurogliaform cells. J. Neurosci. 30, 9898-9909. doi: 10.1523/JNEUROSCI.5883-09.2010

Kay, L. M., Beshel, J., Brea, J., Martin, C., Rojas-Libano, D., and Kopell, N. (2009). Olfactory oscillations: the what, how and what for. Trends Neurosci. 32, 207-214. doi: 10.1016/j.tins.2008.11.008

Kerlin, A. M., Andermann, M. L., Berezovskii, V. K., and Reid, R. C. (2010). Broadly tuned response properties of diverse inhibitory neuron subtypes in mouse visual cortex. Neuron 67, 858-871. doi: 10.1016/j.neuron.2010.08.002

Krook-Magnuson, E., Luu, L., Lee, S. H., Varga, C., and Soltesz, I. (2011). Ivy and neurogliaform interneurons are a major target of $\mu$-opioid receptor modulation. J. Neurosci. 31, 14861-14870. doi: 10.1523/JNEUROSCI.2269-11.2011

Lado, F. A., and Moshe, S. L. (2008). How do seizures stop? Epilepsia 49, 1651-1664. doi: 10.1111/j.1528-1167.2008.01669.x

London, M., Roth, A., Beeren, L., Hausser, M., and Latham, P. E. (2010). Sensitivity to perturbations in vivo implies high noise and suggests rate coding in cortex. Nature 466, 123-127. doi: 10.1038/nature09086 
Major, G., and Tank, D. (2004). Persistent neural activity: prevalence and mechanisms. Curr. Opin. Neurobiol. 14, 675-684. doi: 10.1016/j.conb.2004.10.017

Mitchell, S. J., and Silver, R. A. (2003). Shunting inhibition modulates neuronal gain during synaptic excitation. Neuron 38, 433-445. doi: 10.1016/S08966273(03)00200-9

Olah, S., Fule, M., Komlosi, G., Varga, C., Baldi, R., Barzo, P., et al. (2009). Regulation of cortical microcircuits by unitary GABA-mediated volume transmission. Nature 461, 1278-1281. doi: 10.1038/nature08503

Olah, S., Komlosi, G., Szabadics, J., Varga, C., Toth, E., Barzo, P., et al. (2007). Output of neurogliaform cells to various neuron types in the human and rat cerebral cortex. Front. Neural Circuits 1:4. doi: 10.3389/neuro.04.004.2007

Piredda, S., and Gale, K. (1985). A crucial epileptogenic site in the deep prepiriform cortex. Nature 317, 623-625. doi: 10.1038/317623a0

Price, C. J., Cauli, B., Kovacs, E. R., Kulik, A., Lambolez, B., Shigemoto, R., et al. (2005). Neurogliaform neurons form a novel inhibitory network in the hippocampal CA1 area. J. Neurosci. 25, 6775-6786. doi: 10.1523/JNEUROSCI.113505.2005

Sheffield, M. E., Best, T. K., Mensh, B. D., Kath, W. L., and Spruston, N. (2011). Slow integration leads to persistent action potential firing in distal axons of coupled interneurons. Nat. Neurosci. 14, 200-207. doi: 10.1038/nn.2728

Sheffield, M. E., Edgerton, G., Heuermann, R. J., Deemyad, T., Mensh, B. D., and Spruston, N. (2013). Mechanisms of retroaxonal barrage firing in hippocampal interneurons. J. Physiol. 591, 4793-4805. doi: 10.1113/jphysiol.2013. 258418

Shepherd, G. M. (2011). The microcircuit concept applied to cortical evolution: from three-layer to six-layer cortex. Front. Neuroanat. 5:30. doi: 10.3389/fnana.2011.00030

Simon, A., Olah, S., Molnar, G., Szabadics, J., and Tamas, G. (2005). Gapjunctional coupling between neurogliaform cells and various interneuron types in the neocortex. J. Neurosci. 25, 6278-6285. doi: 10.1523/JNEUROSCI.1431-05. 2005

Suzuki, N., and Bekkers, J. M. (2010a). Distinctive classes of GABAergic interneurons provide layer-specific phasic inhibition in the anterior piriform cortex. Cereb. Cortex 20, 2971-2984. doi: 10.1093/cercor/ bhq046

Suzuki, N., and Bekkers, J. M. (2010b). Inhibitory neurons in the anterior piriform cortex of the mouse: classification using molecular markers. J. Comp. Neurol. 518, 1670-1687. doi: 10.1002/cne.22295
Suzuki, N., and Bekkers, J. M. (2011). Two layers of synaptic processing by principal neurons in piriform cortex. J. Neurosci. 31, 2156-2166. doi: 10.1523/JNEUROSCI.5430-10.2011

Suzuki, N., and Bekkers, J. M. (2012). Microcircuits mediating feedforward and feedback synaptic inhibition in the piriform cortex. J. Neurosci. 32, 919-931. doi: 10.1523/JNEUROSCI.4112-11.2012

Tamamaki, N., Yanagawa, Y., Tomioka, R., Miyazaki, J., Obata, K., and Kaneko, T. (2003). Green fluorescent protein expression and colocalization with calretinin, parvalbumin, and somatostatin in the GAD67-GFP knock-in mouse. J. Comp. Neurol. 467, 60-79. doi: 10.1002/cne.10905

Thuault, S. J., Malleret, G., Constantinople, C. M., Nicholls, R., Chen, I., Zhu, J., et al. (2013). Prefrontal cortex HCN1 channels enable intrinsic persistent neural firing and executive memory function. J. Neurosci. 33, 13583-13599. doi: 10.1523/JNEUROSCI.2427-12.2013

Zhan, C., and Luo, M. (2010). Diverse patterns of odor representation by neurons in the anterior piriform cortex of awake mice. J. Neurosci. 30, 16662-16672. doi: 10.1523/JNEUROSCI.4400-10.2010

Zsiros, V., and Maccaferri, G. (2005). Electrical coupling between interneurons with different excitable properties in the stratum lacunosum-moleculare of the juvenile CA1 rat hippocampus. J. Neurosci. 25, 8686-8695. doi: 10.1523/JNEUROSCI.2810-05.2005

Conflict of Interest Statement: The authors declare that the research was conducted in the absence of any commercial or financial relationships that could be construed as a potential conflict of interest.

Received: 02 January 2014; accepted: 21 February 2014; published online: 13 March 2014.

Citation: Suzuki N, Tang CS-M and Bekkers JM (2014) Persistent barrage firing in cortical interneurons can be induced in vivo and may be important for the suppression of epileptiform activity. Front. Cell. Neurosci. 8:76. doi: 10.3389/fncel.2014.00076 This article was submitted to the journal Frontiers in Cellular Neuroscience. Copyright (C) 2014 Suzuki, Tang and Bekkers. This is an open-access article distributed under the terms of the Creative Commons Attribution License (CC BY). The use, distribution or reproduction in other forums is permitted, provided the original author(s) or licensor are credited and that the original publication in this journal is cited, in accordance with accepted academic practice. No use, distribution or reproduction is permitted which does not comply with these terms. 